\title{
CULTIVATING COLlaborative IMPROVEMENT: AN ACTION LEARNING APPROACH
}

\author{
Rick Middel*, Timothy McNichols ${ }^{\tau}$ \\ *Department of Technology \& Organization, University of Twente, Enschede, the Netherlands \\ ${ }^{\tau}$ IRCHSS Government of Ireland Senior Research Scholar, School of Business Studies, \\ Trinity College, Dublin, Ireland \\ $\underline{\text { h.g.a.middelabbt.utwente.nl }}$
}

\begin{abstract}
As competitive pressure mounts to innovate in the global knowledge economy, many organizations are exploring new ways of collaborating with their supply chain partners. However, the process of implementing collaborative initiatives across disparate members of supply networks is fraught with difficulties. One approach designed to tackle the difficulties of organizational change and inter-organizational improvement in practice is 'action learning'. This paper examines the experiential lessons that arise when cultivating collaborative improvement in an interorganizational learning environment. The authors, acting as action researchers, facilitated a practical learning program in an Extended Manufacturing Enterprise involving a large system integrator in the automotive industry and three of its suppliers. Based on this experience, a practical learning model is offered to promote and facilitate inter-organizational change as part of a collaborative improvement process.
\end{abstract}

\section{INTRODUCTION}

Over the past decade markets have been confronted with a number of changes. Wheelwright \& Clark (1992:2) summarised these changes as: intense international competition; fragmented and demanding markets; and rapidly changing technologies. These changes created new imperatives for competition between organizations, moving increasingly from the level of individual firms to that of networks of companies, leading to the concept of the Extended Manufacturing Enterprise (EME). Busby and Fan (1993) define the EME in terms of manufacturing companies that co-operate closely to maximize the benefits of the business they are involved in (Busby and Fan, 1993). Today's competition no longer takes place between individual companies but between supply chains consisting of multiple, collaborating organizations (Christopher, 1992; Fine, 1998). As firms are forced to re-examine, at a strategic level, the way business is conducted in order to add value and reduce costs it becomes clear that the individual firm is an insufficient entity for identifying improvements (Harland et al. 1999). Firms have to identify and implement improvement initiatives in an inter-organizational context in order to cope with the environmental changes and stay competitive within the global marketplace. The competitive performance of the value chain depends upon learning and the development of the system as a whole entity (Bessant et al., 2003). Considerable emphasis is placed on the ability of firms not only to develop but to continuously learn to keep pace with the competitive environment (Bessant et al., 2003). 
Essentially, learning needs to permeate the boundaries of the single company and disseminate throughout the supply network.

However, the process of cultivating learning across disparate companies within a supply network is fraught with difficulties that encompass a wide array of intra- and interorganizational change issues and working practices. One approach designed to tackle the difficulties of change and inter-organizational improvement in practice is 'action learning'. This reflective learning approach is grounded in a set of structured actions, aimed at operational improvement and inter-organizational learning among companies (Coughlan et al., 2002). To this end, a EU research project CO-IMPROVE (Collaborative Improvement Tool for the Extended Manufacturing Enterprise, G1RD - CT2000 - 00299) was created to foster an action learning approach to promote inter-organizational learning networks. In 2001, the CO-IMPROVE project was started with the goal of developing a tool for the implementation and support of collaborative (inter-organizational) improvement and learning with the expectation of improving performance in a network of organizations.

This paper examines the experiential issues when cultivating collaborative improvement in an inter-organizational learning environment. The first part of this paper presents a literature review of action learning and collaborative improvement in relation to inter-organizational change. In the second section, the action research methodology deployed by the researchers is reviewed. The appropriateness of action research is discussed as a way to achieve a unique insight into the operational and learning patterns involved in a collaborative improvement process. Next, the research base section presents the empirical data in the context of a large Dutch system integrator in the automotive industry and three of its suppliers. A practical action learning model is proposed to categorise the learning phases and position the stages of inter-organizational change. Finally, the discussion section evaluates the results of the project experience to identify the added value of the methodological approach in establishing and facilitating inter-organizational learning.

\section{COLLABORATIVE IMPROVEMENT AND ACTION LEARNING}

Recently, organizational change and especially operational improvements have received much attention in the literature as well as practice. Often in the organizational change literature, a distinction is made between major (radical) and minor (incremental) improvement changes. Incremental is a well-known concept and is widely discussed at the level of the single firm through the literature on Continuous Improvement (Imai, 1986; Bessant and Caffyn, 1997; Boer et al., 2000). However, as competitive pressure mounts to innovate in the global knowledge economy, future survival and success of many companies will depend on the ability to manage and improve inter-organizational processes (Cagliano et al., 2002). Continuous Improvement, therefore, is beyond the scope of intra-company level processes and needs to be extended to the level of 'collaborative' continuous improvement to realize the improvement and learning processes occurring at the inter-company level. The concept of Collaborative Improvement (CoI) is defined as: "a purposeful inter-company interactive process that focuses on continuous incremental innovation aimed at enhancing the EME overall performance" (Cagliano et al., forthcoming; Middel et al., forthcoming).

CoI is simultaneously concerned with bringing about change in the EME, developing the network capabilities, and generating actionable knowledge. It is also an evolving systematic change process that is undertaken to instil collaboration and learning. Working together collaboratively can create learning opportunities that enable a firm to acquire knowledge from partners. Knowledge acquisition refers to skills learned and knowledge acquired by one firm 
from another firm (Norman, 2004). Explicit attention should be paid to the accumulation and development of knowledge which offers competitive advantage and the long-term development of a capability for learning between organizations. According to Crossan and Inkpen (1995), the success of companies working together has been linked to learning and knowledge sharing. The ability of firms to acquire and exploit knowledge has been supported by many authors, such as Cohen and Levinthal (1990) and Huber (1991), and has been linked to a firm's ability to innovate (Fiol, 1996). Therefore, to create an environment conducive to learning, companies need to incorporate a learning program to continually acquire new knowledge.

Recently, 'action learning' has been promoted as a practical strategy in developing organizational learning programs (Weinstein, 1999). Action learning (AL) is an approach to the development of people in organizations, which takes the task as the vehicle for learning (Pedler, 1996; Revans, 1998; Marsick \& O’Neil, 1999; Weinstein, 1999; Yorks et al., 1999). Action learning encourages critical reflection of actions that have been undertaken in order to generate understanding and knowledge that then informs the decision how to act in the future. As such, action learning is an iterative, experiential process involving a cyclical notion of learning. The elements of the cycle are comprised of: (Revans, 1982; Lincoln, 2003):

- Action/Experience

- Question and reflect on this experience

- Draw conclusions and generate knowledge

- Plan new action

Action learning has proven to be a useable and useful approach for managers learning to take their action/experience, subject it to critical inquiry and reflect with the support of a group, in order to develop future actions (Dilwoth and Willis, 2003; McGill and Beaty, 1995). Although action learning is widely adopted approach by managers in their own companies, it can provide a useful approach for managers and companies in an inter-organizational setting as well (Coughlan and Coghlan, 2004).

Action learning makes a key distinction from other types of learning through its continuous process of learning and reflection in organizational practice. In action learning, the starting point is the action and through reflection this becomes learning-in-action. Action learning has six distinct interactive components (Marquardt, 1999):

1. A problem - whereby complex organizational issues which touch on different parts of the organization and which are not amenable to expert solutions are worked on.

2. The group - which comprises a typical six to eight members who care about the problem, know something about it and have the power to implement solutions

3. The questioning and reflective process - the formula for learning in action learning is $\mathrm{L}=\mathrm{P}+\mathrm{Q}$ (Revans, 1998). L stands for learning, $\mathrm{P}$ for programmed learning (i.e. current knowledge in use, already known, what is in books etc.) and $\mathrm{Q}$ for questioning. In this regard, action learning has close relationships with other processes which focus on learning in action, like action research and experiential learning, and continuous improvement processes such as Kaizen, TQM and TPM (Coughlan et al., 2002)

4. The commitment to taking action - action learning is based on the premise that no real learning takes place unless and until action is taken. Implementation of action, rather than recommendations to other, is central. 
5. The commitment to learning - action learning aims at going beyond merely solving immediate problems. An increase in the knowledge and capacity to better adapt to change is more important.

6. The facilitator - action learning groups benefit from having a facilitator, one who plays a variety of roles for the group such as coordinator, catalyst and climate setter.

One advantage of an action learning program is the removal of participants from their day-today work routines and to provide an opportunity for reflective learning. Although the participants are performing task-based projects by a certain deadline, it is important that the accomplishment of the task does not obscure the process of learning. However, without reflection and feedback action learning would be no different from a normal problem solving initiative within the company. Therefore, it is essential that active and disciplined feedback is provided by objective sources (Davis and Hogarth, 1992). Facilitators provide a useful source of feedback in action-learning experiences. Through structured feedback sessions and evaluation techniques, facilitators promote discussion and reflection to foster and reinforce reflective learning by the participants. Facilitators employ questions and discussions rather than statements or lectures to guide learning opportunities.

The reflective learning opportunities should be staged with regular frequency. Often in projects, reflection on learning is conducted on the last day of a program (Conger and Toegel, 2003). However, in order to get the most out of the learning, there should be regularly programmed opportunities for participants to reflect on learning throughout the project. Regular reflection forces participants to reflect more directly on immediate moments and events, and so learning tends to be richer and focussed around specific incidents. In association with other research on feedback, it is most useful to learners when focussed on recent events (Conger and Toegel, 2003). When reflections are tied to immediate events, the likelihood that more knowledge will be acquired from the experience will increase. Moreover, by building in reflection during the program the participants can learn the process themselves in order to reflect on their actions and ultimately deploy this knowledge in future initiatives.

This study focuses on the application of an action learning program involving collaborative improvement in an EME. Specifically, this paper will investigate an action learning process grounded in a structured intervention based around a set of learning phases. The remainder of this paper sets out to examine the impact of an action learning program on the operational and learning outcomes in an inter-company setting.

\section{METHODOLOGY}

An immersive field study provided the basis for this investigation into the action learning process within an Extended Manufacturing Enterprise. While managers and companies engage explicitly in action learning cycles, researchers can use, in parallel, an action research methodology to generate actionable knowledge on collaborative improvement (Middel et al., 2005). Action Research (AR) is a cyclical process of diagnosing, action planning, action taking, evaluating and specifying learning (Lau, 1999). This methodology focuses on research in action, rather than research about action, in which members actively participate in the cyclical process. Several broad characteristics define action research (Eden and Huxham, 1996; Coghlan and Brannick, 2001; Coughlan and Coghlan, 2002):

- Research in action, rather than research about action;

- Participative; 
- Concurrent with action;

- A sequence of events and an approach to problem solving.

The AR approach was adopted to facilitate and stimulate the development of a capability for improvement and learning process within the EME. The findings reported in this paper were uncovered through an AR approach where the researchers were both managing and studying the project at the same time (Coghlan and Brannick, 2001; Coughlan and Coghlan, 2002). This approach enabled the researchers to interact with the EME while the companies engaged in the process of learning in action. As stated by Westbrook (1995) a main contribution of action research to learning, which is not available to other methods, is that when participants involve themselves in change experiments, they engage in non-trivial learning, and they think and reflect seriously on what they are doing.

The AR approach develops explicitly the relational participation between the companies involved and the researchers and was ultimately guided by a reflexive concern for practical outcomes. Consequently, this extends and deepens the cycle of learning that involved refining thinking, reviewing assumptions, re-evaluating the methods that are used, and checking knowledge, or knowing-in-action (Schön, 1987), that shapes the action. AR uses the results of the reflection, or reflection-in-action (see Schön, 1987), to plan and propose new lines of inquiry within the project. Both $\mathrm{AR}$ and action learning are complimentary in nature, involving cycles of learning from experience then reflection on that action (Dick, 1997), which is intended to change and improve practices. Through the adoption and implementation of AR within this specific setting, it is inclusive of a plurality of knowing, as the practical and technical knowing within the EME is complemented by the development of theoretical knowledge on the process of CoI (Coughlan et al., 2004).

The authors, as participant-observers, were actively involved in 14 monthly, one-day workshops over a period of 18 months. In addition to the participant observations, multiple sources of evidence were gathered to provide further support for the outcomes of the learning process. This data collection process drew on a wide range of interventions - self-assessment instruments, documents, presentations at meetings and feedback by participants. Data analysis was based on reflective notes of each workshop, interviews with each participant and documents on results of $\mathrm{CoI}$ initiative. The interpretation of the data was structured around a collation of all the information into operational and learning outcomes. In this way, the researchers were able to validate the data, generate understanding through a reflection and synthesis of the effects of implementing an action learning program.

\section{RESEARCH BASE}

This section reports on the context of the research by introducing the Dutch EME, comprising one system integrator and three of its first-tier suppliers.

The System Integrator (SI) is a limited company, who specialises in 'Motion Control'-systems for different markets, such as the automotive, truck, marine, medical and agriculture market. The company sees itself in a niche market, predominantly automotive and truck. The competition is known and it is intense with a main emphasis on price. The company observes a shift in the market towards a commodity market. In this new market, the order-winning criterion is price whereas quality and technology are qualifiers. For a company in the automotive industry nowadays, a main challenge is to constantly monitor the cost-structure in order to remain profitable. Recently, price pressure from the Original Equipment Manufacturers (OEM) has led to a decrease of prices and contracts on long-term delivery 
schedules. Therefore, the company has mounts a strategic objective to produce zero-defect products together with the lowest total cost from world-class suppliers to satisfy their requirements on quality, cost and delivery.

The suppliers selected by the system integrator to participate in the project all represent different types of relationships and deliver different categories of products. This selection means that information and communication can pass freely throughout the whole group without running the risk of giving away (or transferring) sensitive information to competitors. The companies within the Dutch EME and a short description are listed in Table 1.

Table 1: Companies in the Dutch EME

\begin{tabular}{|l|l|l|l|}
\hline Company & \#employees & Geography & Products \\
\hline System Integrator & 425 & $\begin{array}{l}\text { The } \\
\text { Netherlands } \\
\text { (East) }\end{array}$ & $\begin{array}{l}\text { Complete electro-hydraulic systems for } \\
\text { the automotive and truck industries. }\end{array}$ \\
\hline Supplier 1 & 200 & $\begin{array}{l}\text { The } \\
\text { Netherlands } \\
\text { (South) }\end{array}$ & $\begin{array}{l}\text { Assembled plastic precision parts for } \\
\text { the automotive medical and } \\
\text { pharmaceutical industry. }\end{array}$ \\
\hline Supplier 2 & 55 & $\begin{array}{l}\text { The } \\
\text { Netherlands } \\
\text { (East) }\end{array}$ & $\begin{array}{l}\text { Fine-mechanical parts for high-tech } \\
\text { industry. The company supplies parts } \\
\text { for the pump for opening the roof }\end{array}$ \\
\hline Supplier 3 & 160 & $\begin{array}{l}\text { Germany } \\
\text { (West) }\end{array}$ & $\begin{array}{l}\text { Cylinder-tubes for the automotive } \\
\text { industry. }\end{array}$ \\
\hline
\end{tabular}

The underlying reason for the SI selection process has been the fact that these suppliers are perceived as strategically significant. Furthermore, they are viewed as dedicated partners that fully support the SI in assembling and delivering the systems of the SI. All three suppliers selected for involvement in the research project represent a unique relationship characterized by certain contextual factors as listed in Appendix A

\section{DYAD 1 - SI \& SUPPLIER 1}

Supplier 1 is an automotive supplier to the SI for more than 10 years. Historically, there has been a close relationship between the two companies with frequent interaction. Currently, the SI ranks as a top ten customer accounting for 3\% of sales volume. Both participants expressed low levels of uncertainty in their trading partner relationship as well as their forecasting (or production) capabilities. Moreover, supplier 1 is viewed as a dedicated partner in assembling and delivering systems for numerous years being awarded preferential supplier status. Both parties view the relationship as 'trustworthy' and perceive the other as adhering to agreements and consistent in business dealings. The most important aspect of the relationship according to the supplier is "complimentary knowledge sharing". On the other hand, the SI buyer identifies "trust, competitive delivery, quality and costs" as the most significant features of the relationship.

Although the SI has never been involved in the supplier's internal processes, these firms have previously engaged in joint projects. Historically, joint initiatives were focussed on problem 
resolution projects based a mutual setting of goals to obtain a certain level of improvement. For example, two previous projects led to specific goals targeting levels of quality improvements (i.e. defect rate) and logistic improvements (i.e. delivery targets). Elements of Early Supplier Involvement (ESI) are evident particularly in the co-designing of replacement products utilizing less expensive and more robust materials.

\section{DYAD 2-SI \& SUPPLIER 2}

Supplier 2 has supplied customized parts for over 10 years. A high dependency exists on the SI represented by $20 \%$ of sales volume. Over the past few years, there has been mutual engagement in product and process improvement projects. Unique among the Co-Improve suppliers, a mutual Kanban system was established to improve the production process. This improvement project has been beneficial for both organizations through "more tightly linked mutual processes, improved stock efficiency and increased area for stock holding" (SI Buyer). Today, a more reactive approach exists whenever faults, problems or quality issues surface this triggers the need for improvement initiatives between the companies.

In the past, the relationship has been through turbulent periods, which has damaged the supplier's perception of trust:

"It is hard to trust them [sic SI]. Because two years ago, half the production of a part was taken away and awarded to a Spanish competitor who quoted a lower price per unit and they did not even tell us they were searching for another supplier. But after a year, they were not getting the quality and delivery they expected.... and they moved all the production back to us. (Sales Manager, Supplier 2).

The supplier manager expressed concerns that the collaboration involved in this project would be limited. The need to develop more trust was emphasized in order to move towards greater collaboration. Commenting on the relationship:

"no regular basis for collaborative improvement exists at the moment...improvements are based on day to day problems." (Sales Manager, Supplier 2)

\section{DYAD 3 - SI \& SUPPLIER 3}

The relationship between Supplier 3 and the SI is very new. In 1999, the supplier was approached by the SI with the prospect of manufacturing and supplying metal cylinder tubes related to truck hydraulic systems. Subsequently, they signed a prospective trial production agreement contract for an initial trial run.

Both participants expressed a 'medium to high' level of uncertainty in the relationship with the other firm and in their corresponding production/forecasting capabilities. Without any history, there is an absence of any track record of improvement activities. Not surprisingly, both respondents could not comment on the 'trustworthiness' of their new partner or consistency in business transactions or promises. However, both respondents indicated they expected to be 'long-term' trading partners. According to the SI Quality Manager, the most important aspect of the relationship is "new process development and raw material sourcing". The project manager for the supplier described the most important issue is "to have a solid partnership with good communication". 


\section{The Practical Learning APPROACH}

The Dutch learning network is comprised of a system integrator in the automotive industry, three of its first-tier suppliers and two facilitators (see Figure 1).

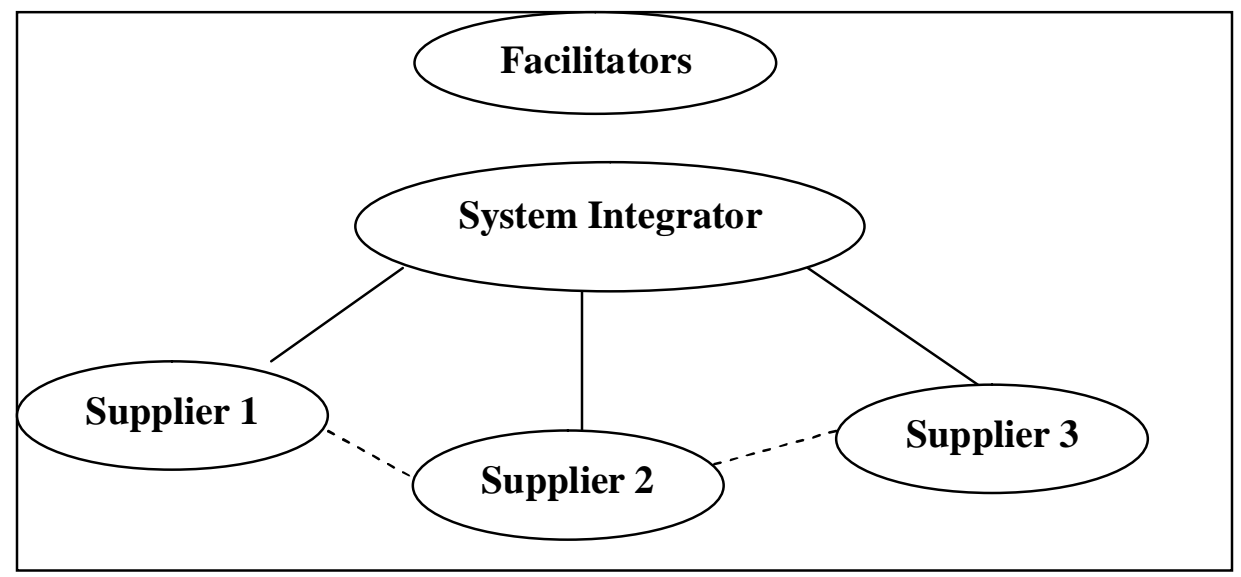

Figure 1: Learning network

In this study, an action learning program has been applied to the process of collaborative improvement and inter-organizational learning between the network participants in order to enhance the overall performance of the total EME. To examine the detailed approach undertaken, the six components of action learning (Marquardt, 1999) were identified in the Dutch learning network (refer to Table 2).

Table 2: Action Learning in the Dutch EME

\begin{tabular}{|l|l|}
\hline Action Learning & Action Learning in the Dutch EME \\
\hline A problem & $\begin{array}{l}\text { Immediate practical concerns involving } \\
\text { operational issues between system integrator } \\
\text { and suppliers. }\end{array}$ \\
\hline The group & $\begin{array}{l}\text { An inter-organizational network comprising a } \\
\text { system integrator and three first-tier suppliers }\end{array}$ \\
\hline The questioning and reflective process & $\begin{array}{l}\text { Monthly workshops provided an opportunity } \\
\text { for reflective learning (presentation and } \\
\text { discussion of improvement initiatives; } \\
\text { reflection on process and progress; and } \\
\text { recognition and diffusion of learning). }\end{array}$ \\
\hline The commitment to taking action & $\begin{array}{l}\text { The network is committed to work on } \\
\text { practical concerns in inter-organizational } \\
\text { processes. }\end{array}$ \\
\hline The commitment to learning & $\begin{array}{l}\text { The network is committed to reflect and learn } \\
\text { from immediate actions and events as part of } \\
\text { the collaborative improvement process. }\end{array}$ \\
\hline The facilitator & $\begin{array}{l}\text { Members of University of Twente and Trinity } \\
\text { College Dublin acted as learning coaches. }\end{array}$ \\
\hline
\end{tabular}


The action learning approach was implemented in the Dutch EME over a period of 18 months through a cycle of 14 workshops. These workshops were organised through mutual consent with the participants on a monthly basis, schedules permitting. The facilitators in partnership with the SI Quality Manager structured the workshops to engage companies in collaborative improvement activities, involving processes of diagnosing, fact-finding, implementation and evaluation of improvement actions. Moreover, the process of action learning emphasised the importance of a structured questioning and reflective process within the Dutch learning network. The detailed action learning approach adopted in the EME can be summarised in four phases, each differing in length:

\section{Phase 1: Setting up the Learning Network}

The kick-off meeting of the project involved an introductory presentation on the Action Learning approach. This introduction was designed to encourage participants to think differently, be exposed to new ideas and new knowledge on collaboration and tackling initiatives (Garvin, 1994).

\section{Phase 2: Identifying Learning Requirements}

The selection of projects in collaborative operations was an important step in identifying the improvement areas. The researchers interviewed the representatives of the companies and carried out further assessments with regard to the level of operational integration and collaborative improvement maturity. This resulted in a list of possible improvement projects between the SI and the suppliers from which the companies selected specific improvement projects in alignment with their identified goals. This activity enabled the facilitators to focus on the learning required to extend the improvement beyond one improvement cycle. This phase was repeated, as required, throughout the program in order to identify further improvement goals and learning targets.

\section{Phase 3: Facilitation of Action Plans}

After the companies selected a project, they start working on the collaborative improvement activity, whereby the researcher participated as a facilitator for all the companies in the project. A series of workshops were organised to plan the actual learning cycle:

- Identify a collaborative improvement project between the companies and devise an action plan which scheduled tasks between the workshops;

- Present and discuss the improvement activities and results in plenum at the workshop;

- Reflect on the process and progress of the project in order for all the EME participants to learn and support the process.

\section{Phase 4: Evaluation and Reflection of Learning}

In order to learn from the issues, experience and practice emanating out of the improvement initiatives, the facilitator initiated an evaluation and reflective practice. This practice emphasised the learning aspects from the projects:

- Complete a reflective questionnaire instrument to identify and discuss the emergent issues at group level 
- Disseminate the learning moments, experience and knowledge throughout the entire EME.

After completion of phase four, the learning cycle loops back into phase two. This feedback and reflective learning loop continues for the duration of the program. A graphical display of the four phases identified in this practical learning is displayed in Figure 2. This SIFE model offers a general guideline to organizing an inter-organizational action learning approach.

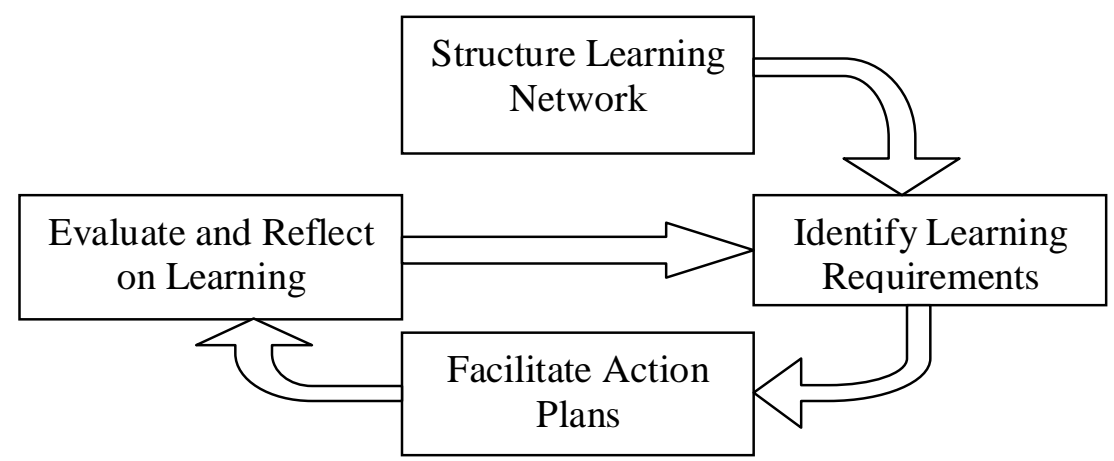

Figure 2: The SIFE Model for Organizing Practical Learning

\section{DISCUSSION}

In this Dutch EME, the action learning approach has been operationalized in a real-world environment with pragmatic people working on real problems and achieving measurable results. During each workshop, presentations emphasized the progress and process of the improvement initiatives, which were discussed and reflected on in plenum. The most sustainable element of this project was the process and method undertaken to stimulate practical learning by the people involved, not the one-off improvement experience. Hence, explicit attention was given to the process of diffusing knowledge, experiences and lessons learned as part of the collaborative improvement initiatives. The success of the action learning program showed a progression from the conception of an idea, through targeting improvement actions to solving specific problems in a systematic way. For example, participants started to consider project activities as opportunities to develop a closer relationship. This relationship improvement has solved many immediate operational concerns for the people involved.

To determine the impact of the program, the action researchers composed reflective notes and interviewed each participant in terms of operational and learning outcomes. An overview of the initiated improvement projects and the outcomes achieved are given in Table 3:

Table 3: Operational \& Learning Outcomes (by Improvement Initiative)

\begin{tabular}{|c|l|l|l|l|}
\hline $\begin{array}{c}\text { Collaborative } \\
\text { Improvement } \\
\text { Initiative }\end{array}$ & \multicolumn{1}{|c|}{$\begin{array}{c}\text { Improvement } \\
\text { activity }\end{array}$} & $\begin{array}{c}\text { Departments } \\
\text { Involved }\end{array}$ & $\begin{array}{c}\text { Operational } \\
\text { Outcome }\end{array}$ & $\begin{array}{c}\text { Learning } \\
\text { Outcome }\end{array}$ \\
\hline Dyad 1 & $\begin{array}{l}\text { Redesign of a } \\
\text { product, which can }\end{array}$ & $\begin{array}{l}\text { Purchasing, } \\
\text { Engineering, }\end{array}$ & $\begin{array}{l}\text { Cost reduction and } \\
\text { increase of the }\end{array}$ & $\begin{array}{l}\text { Increased } \\
\text { awareness of }\end{array}$ \\
\hline
\end{tabular}




\begin{tabular}{|c|c|c|c|c|}
\hline & $\begin{array}{l}\text { cause severe } \\
\text { problems during } \\
\text { malfunction in the } \\
\text { system of the SI }\end{array}$ & $\begin{array}{l}\text { Sales, } \\
\text { Quality }\end{array}$ & $\begin{array}{l}\text { quality of the } \\
\text { product. The } \\
\text { supplier is able to } \\
\text { reduce internal } \\
\text { scrape rate by } 33 \%\end{array}$ & $\begin{array}{l}\text { need to } \\
\text { communicate and } \\
\text { share information } \\
\text { more regularly. } \\
\text { Closer } \\
\text { collaboration to } \\
\text { overcome } \\
\text { problems }\end{array}$ \\
\hline Dyad 1 & $\begin{array}{l}\text { Proposal to } \\
\text { produce an existing } \\
\text { product of the SI of } \\
\text { aluminum in } \\
\text { plastic }\end{array}$ & $\begin{array}{l}\text { Purchasing, } \\
\text { Engineering, } \\
\text { Sales, } \\
\text { Quality }\end{array}$ & $\begin{array}{l}\text { Expected } \\
\text { outcomes are } 50 \% \\
\text { cost reduction for } \\
\text { the SI and increase } \\
\text { in Sale for the } \\
\text { supplier }\end{array}$ & $\begin{array}{l}\text { The inducement } \\
\text { for improvement } \\
\text { is not always a } \\
\text { practical problem } \\
\text { but can create } \\
\text { more pro-active } \\
\text { opportunities for } \\
\text { improvement }\end{array}$ \\
\hline Dyad 2 & $\begin{array}{l}\text { Cleanliness of } \\
\text { products }\end{array}$ & $\begin{array}{l}\text { Quality, } \\
\text { Sales, } \\
\text { Purchasing, } \\
\text { Production }\end{array}$ & $\begin{array}{l}\text { Increase in sales } \\
\text { from SI to } \\
\text { supplier. } \\
\text { Reduction by } \\
\text { reject rate by SI }\end{array}$ & $\begin{array}{l}\text { Need for project } \\
\text { planning. } \\
\text { Importance of } \\
\text { information } \\
\text { sharing between } \\
\text { the companies }\end{array}$ \\
\hline Dyad 3 & $\begin{array}{l}\text { Information and } \\
\text { communication on } \\
\text { specifications of } \\
\text { products }\end{array}$ & $\begin{array}{l}\text { Purchasing, } \\
\text { Sales }\end{array}$ & N.A. & $\begin{array}{l}\text { Increased } \\
\text { information } \\
\text { exchange and } \\
\text { awareness of } \\
\text { need for } \\
\text { improving } \\
\text { communication }\end{array}$ \\
\hline Dyad 3 & $\begin{array}{l}\text { Analyse and } \\
\text { evaluate a change } \\
\text { in tooling concept } \\
\text { by the supplier }\end{array}$ & $\begin{array}{l}\text { Purchasing, } \\
\text { engineering, } \\
\text { Sales }\end{array}$ & N.A. & $\begin{array}{l}\text { Increased insight } \\
\text { in organizational } \\
\text { structure and } \\
\text { communication } \\
\text { flows on both } \\
\text { sides }\end{array}$ \\
\hline
\end{tabular}

Prior to the action learning program, reflection on learning was not performed due to operational priorities within the EME. Consequently, at the start of the program, learning was not an integral part of collaborative relationships and $\mathrm{CoI}$ initiatives. For instance, when the SI and the suppliers initiated CoI activities and engaged in action learning, several problems and obstacles with regard to learning were identified. The situation improved gradually over time. However, participants were constantly struggling with balancing operational priorities and learning as part of CoI. Hence, facilitation by the SI and the participant-observers was perceived as essential by the participants in the action learning program. This facilitation process enabled a distinction to be drawn between the learning outcomes and the operational outcomes. 
Initially, there lacked a mutual understanding between the SI and its suppliers on the concept of CoI, which had a negative effect on the level of openness between the companies. This often resulted in political behavior from the suppliers towards the SI. The suppliers had the impression that this was another way of implementing cost reduction and quality programs. Especially in Dyad 2, the perceived negative experiences from past collaborative initiatives led to a cautious and reactive behavior from the side of the supplier. The first phase of the action learning program was organized to address this concern by focusing on creating a mutual understanding of $\mathrm{CoI}$ and developing a sense of direction.

The improvement activities engaged at the level of customer-supplier relationships, but the progress and the results were constantly shared with the entire EME in monthly workshops. The participants perceived these frequent face-to-face meetings as "fuel" for the efficiency and effectiveness of collaborative improvement activities. During these meetings, the companies were able to align the process of improvement with regard to the progress and expected outcomes. Another benefit was that attention was increased in the time before, during and after the workshops, which maintained the momentum and speed within the improvement projects. Moreover, these regular EME meetings provided the participants with the opportunity to reflect and learn not only from improvement activities but also from other delegates within the program. Just as organizational learning is very difficult, interorganizational barriers accentuated the attainment of learning on an EME level. Hence, facilitation was required to emphasize the importance of a structured questioning and reflective process as part of the intervention. Importantly, this process involved the participants sharing learning and experiences across the network thus enabled benefits from an EME perspective.

Overall, there has been evidence of an improvement in communication, information sharing and perception of the relationship between all the participants involved. Specifically, all the suppliers reported an increase in the frequency of meetings, quality of communication, and improvement in their relationship with the SI.

At times, however, the operational aspects of the improvement projects did not progress according to the initial projection of the action plans. For example, the Dyad 3 relationship was continually ensnared in the trial stage for the duration of the Co-Improve project, since contracts were not exchanged to begin full production and delivery. However, the action learning program overcame this obstacle by identifying improvement activities and targeting associated learning requirements that still provided a learning outcome. By proposing two non-operational focused activities, the facilitators targeted information exchange, communication flows and relationship improvement between the companies.

In reality, progress between organizations and individuals is often derailed by unforeseen obstacles, the intervention program has to provide flexibility to steer an alternative course yet robust enough to counteract derailment.

This project provided the opportunity to apply an action learning approach between collaborating companies. The design of the action learning program has been build around a structure of regular workshops divided in four key phases. After 18 months, the participants indicated that they recognized the importance of creating a learning environment, in which they can and do share information and communicate openly. Not only did they display the willingness to collaborate, communicate and share information, they also displayed to understand and learn from other's perspective and develop a sense of direction with regard to $\mathrm{CoI}$ and their relationship. An anecdotal indicator of success is that the SI decided to adopt this approach in order to cultivate a strategic improvement initiative through a 'roll out' to 
other suppliers. According to one supplier, the action learning process enabled them to "work together more closely in an open and trustworthy way".

\section{Conclusions}

Collaborative improvement and learning between organizations in a network is vital in today's global marketplace in order to cope with the dynamic environment and build competitive advantage. Action learning is an approach that is designed to tackle the difficulties of organizational change and inter-organizational innovation in practice. Action learning provides a practical methodology to instill a capacity for learning as part of the collaborative improvement process. Through the enactment of an integrated set of action to be executed within the EME, it contributes towards a continuous process of learning in interorganizational practice.

A critical evaluation and interpretation of the adopted approach suggest some lessons learned.

1. Establish an AL group of members comprised of different functional areas but with mutual concern for the project.

2. Ensure that all group members are indoctrinated into the adopted AL approach by establishing clear roles and responsibilities in the project and specifying expectations from all participants.

3. Evaluate unique contextual factors impacting the relationship when organizing and facilitating network action plans.

4. Facilitators must consciously and deliberately enforce the AL phases (Action/experience, question and reflect on this experience, draw conclusions and generate knowledge, plan new action).

5. Alter the AL phases, as required, to counterbalance any turbulence experienced during the intervention program.

Within CoI, explicit attention needs to be paid to the accumulation and development of knowledge which offers competitive advantage and the long-term development of a capability for learning between organizations. Hence, companies need to create an environment that enables learning in an inter-organizational setting and incorporate a flexible, yet robust learning program to continually acquire new knowledge. Capturing as much knowledge as possible during the project cycle can greatly reduce the actions required in future initiatives and other EME participants can learn from this knowledge repository to use within their own value networks.

Action learning can play a key role in cultivating improvement initiatives and promoting effective learning in collaborative relations between supply chain partners. The SIFE model offers a broad structure to support collaborative learning networks with the flexibility to adapt to different circumstances as required. Implementing a learning strategy is difficult in practice, however managers and their collaborative partners who fail to 'maximise the opportunity' to learn from mutual improvement processes are in danger of falling behind in the competitive marketplace.

\section{REFERENCES}

Bessant, J., Caffyn, S. (1997), "High-involvement Innovation through Continuous Improvement”, International Journal of Technology Management, 14 (1), 7-28

Bessant, J., R. Kaplinsky, R. Lamming (2003), "Putting supply chain learning into practice”, International Journal of Operations \& Production Management, 23 (2), 167- 184 
Boer, H., Berger, A., Chapman, R., Gertsen, F. (2000), CI changes: from suggestion box to organizational learning, Continuous Improvement in Europe and Australia, Aldershot, Ashgate Publishing Ltd.

Busby, J.S. and Fan, I.S. (1993), The extended manufacturing enterprise: its nature and its needs, International journal of technology management, 8 (3,4,5), 294-308

Cagliano, R., Caniato, F., Corso, M., Spina, G. (2002), 'Collaborative Improvement in the Extended Manufacturing Enterprise: some empirical evidence and a preliminary business model', In conference proceedings POM2002.

Cagliano, R., Caniato, F., Corso, M. and Spina, G. (forthcoming) "Implementing collaborative Improvement: lessons from an action research process", International Journal of Production Planning \& Control.

Cohen, W.M., Levinthal, D.A. (1990), Absorptive Capacity: a new perspective on learning and innovation, Administrative Science Quarterly, 35 (1), 128-152

Christopher, M. (1992), Logistics and Supply Chain Management, Pitman Publishing, London

Conger, J. and Toegel, G. (2003), Action learning and multi-rater feedback as leadership development interventions: Popular but poorly deployed, Journal of Change Management, 3 (4), 332-348.

Coghlan, D. and Brannick, T (2001): Doing Action Research in Your Own Organization, Sage: London

Coughlan, P. and Coghlan, D. (2002): Action Research for Operations Management, International Journal of Operations and Production Management, 22 (2): 220-240

Coughlan, P., Coghlan, D., Brennen, L., Lombard, F., McNichols, T., Nolan, R. (2002), Action learning in the extended manufacturing enterprise: towards an advanced implementation of the NALP approach, In: Smeds, R (Ed.) Proceedings of the 4th International CINet conference on Continuous Innovation in Business Processes and Networks, Simlab, Helsinki University of Technology, Finland, 197-208

Coughlan, P. and Coghlan, D. (2004), Action Learning: Towards a framework in inter-organisational settings, Action Learning: Research and Practice, 1 (1), 43-61

Coughlan, P., Coghlan, D., Brennan, L. (2004): Organizing for Research and Action: Implementing Action Researcher Networks, Systemic Practice and Action Research, 17 (1): 37-49

Crossan, M.M., Inkpen, A.C. (1995), The subtle art of learning through alliances, Business Quarterly, 60 (2), 68 78

Davis, H. L. and Hogarth, R. M. (1992) 'Rethinking Management Education: A View from Chicago', in Selected Papers from the Graduate School of Business at the University of Chicago', Chicago, IL.

Dick, B. (1997): Action learning and action research [On line], Available at http://www.scu.edu.au/schools/gcm/ar/arp/actlearn.html

Dilworth, R.L., and Willis, V.J. (2003), Action Learning: images and pathways, Malabar, Krieger

Eden, C., and Huxham, C. (1996): Action Research for the study of organizations, In Clegg, S., Hardy, C. and Nord, W. (ed), Handbook of Organization Studies, Sage Publications, London: 526-542

Fine, C. (1998) Clockspeed: Winning Industry Control in the Age of Temporary Advantage, Perseus Books.

Fiol, C.M. (1996), Squeezing harder doesn't always work: continuing the search for consistency in innovation research, Academic Management Review, 21 (4), 1012-1021

Garvin, D. (1994), "Building a learning organisation", Business Credit, 96 (1), 19-28.

Harland, C.M., Lamming, R.C., and Cousins, P.D. (1999), Developing the concept of supply strategy, International Journal of Operations \& Production Management, 19 (7), 650-673

Huber, G.P. (1991), Organizational learning: the contrbuting processes and the literatures, Organization Science, $2(1), 88-115$

Imai, M. (1986), Kaizen. The key to Japan's Competitive Success, London, McGraw-Hill Publishing Company

Lau, F. (1999), Toward a framework for action research in information systems studies, Information Technology \& People, 12 (2), 148-175

Lincoln, S. (2003), Learning through action: Management development through action learning and action research, Development and Learning in Organizations, 17 (6), 12-14 
Marquardt, M. (1999), Action learning in action, Palo Alto, CA, Davies-Black

Marsick, V., \& O'Neil, J. (1999), “The many faces of action learning”, Management Learning, 30 (2), 159-176

McGill, I., and Beaty, L. (1995), Action Learning, London, Kogan Page

Middel, H.G.A., Gieskes, J.F.B. and Fisscher, O.A.M. (forthcoming), "Driving collaborative improvement processes", International Journal of Production Planning \& Control

Middel, H.G.A., Brennan, L., Coghlan, D. and Coughlan. P. (2005), The Application of Action Learning and Action Research in Collaborative Improvement within the Extended Manufacturing Enterprise, In: Kotzab, H., Seuring, S., Müller, M., Reiner, G. (Eds.), Research Methodologies in Supply Chain Management, Physica, Heidelberg, 365-380

Norman, P.M. (2004), Knowledge acquisition, knowledge loss, and satisfaction in high technology alliances, Journal of Business Studies, 57, 610-619

Pedler, M. (1996), Action learning for managers ( $1^{\text {st }}$ edition), Lemos \& Crane, London

Revans, R. (1982), The Origins and Growth of Action Learning, Chartwell-Bratt, London, UK

Revans, R. (1998), ABC of Action Learning, Lemos \& Crane, London.

Schön, D.A. (1987), Educating the Reflective Practioner, Toward and New Design for Teaching and Learning in the Professions, Jossey-Bass Publishers, San Fransisco

Westbrook, R. (1995): Action Research: a new paradigm for research in production and operations management, International Journal of Operations \& Production Management, 15 (12): 6-20

Weinstein, K. (1999), Action Learning: A Practical Guide. Gower, London.

Wheelwright, S.C., Clark, K.B. (1992), Revolutionizing Product Development, Quantum Leaps in Speed, Efficiency and Quality, The Free Press, New York, United States of America

Yorks, L., O'Neil, J. \& Marsick, V. (1999), Action Learning: Successful Strategies for Individual, Team and Organizational Development, Berrett-Koehler, San Francisco. 


\section{APPENDIX A}

Inter-Organizational Relationship Characteristics

\begin{tabular}{|c|c|c|c|c|c|c|c|}
\hline \multirow{2}{*}{\multicolumn{2}{|c|}{ Characteristics }} & \multicolumn{2}{|c|}{ Dyad 1} & \multicolumn{2}{|c|}{ Dyad 2} & \multicolumn{2}{|c|}{ Dyad 3} \\
\hline & & $S I$ & Supplier 1 & $S I$ & Supplier 2 & $S I$ & Supplier 3 \\
\hline \multicolumn{2}{|c|}{ Length of Relationship } & \multicolumn{2}{|c|}{$10+$ Years } & \multicolumn{2}{|c|}{$10+$ years } & \multicolumn{2}{|c|}{ New } \\
\hline \multicolumn{2}{|r|}{$\begin{array}{l}\text { Volume of Sales / } \\
\quad \text { Purchases }\end{array}$} & $2 \%$ & $3 \%$ & $1.5 \%$ & $20-25 \%$ & $\begin{array}{c}0 \% \\
\text { (Potential } \\
2 \%)\end{array}$ & $\begin{array}{c}0 \% \\
\text { (Potential } \\
3 \%)\end{array}$ \\
\hline \multicolumn{2}{|c|}{ Importance of Relationship } & High & Medium & Medium & High & Medium & Medium \\
\hline \multicolumn{2}{|c|}{$\begin{array}{c}\text { Future Relationship } \\
\text { (Length) }\end{array}$} & $\begin{array}{l}\text { Very long- } \\
\text { term }\end{array}$ & $\begin{array}{l}\text { Very long- } \\
\text { term }\end{array}$ & $\begin{array}{l}\text { Long- } \\
\text { Term }\end{array}$ & $\begin{array}{l}\text { Very long- } \\
\text { term }\end{array}$ & Long-Term & Long-Term \\
\hline \multicolumn{2}{|r|}{ Shared Goals } & \multicolumn{2}{|c|}{$\begin{array}{l}\text { Yes, Cost and Logistics } \\
\text { targets }\end{array}$} & \multicolumn{2}{|c|}{$\begin{array}{c}\text { Yes, Quality and } \\
\text { Technical } \\
\text { specifications targets }\end{array}$} & \multicolumn{2}{|c|}{ No } \\
\hline \multicolumn{2}{|c|}{ History of Projects } & \multicolumn{2}{|c|}{ Yes } & \multicolumn{2}{|c|}{ Yes } & \multicolumn{2}{|c|}{ No History } \\
\hline \multirow{5}{*}{ 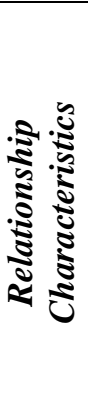 } & Dependency & High & $\begin{array}{l}\text { Low to } \\
\text { Medium }\end{array}$ & High & $\begin{array}{l}\text { Medium to } \\
\text { High }\end{array}$ & Low & Low \\
\hline & $\begin{array}{c}\text { Uncertainty in } \\
\text { Partner Production }\end{array}$ & None & None & Low & Medium & $\begin{array}{l}\text { Medium to } \\
\text { High }\end{array}$ & High \\
\hline & $\begin{array}{l}\text { Partnership } \\
\text { Uncertainty }\end{array}$ & Low & Low & Low & Medium & $\begin{array}{l}\text { Medium to } \\
\text { High }\end{array}$ & $\begin{array}{l}\text { Medium to } \\
\text { High }\end{array}$ \\
\hline & Trust & High & High & High & $\begin{array}{c}\text { Low- } \\
\text { Medium }\end{array}$ & - & - \\
\hline & Power & High & High & High & Medium & $\begin{array}{l}\text { Low to } \\
\text { Medium }\end{array}$ & Low \\
\hline
\end{tabular}

